\title{
O CAPITALISMO IMATERIAL E A PRODUÇÃO DE SI, SEGUNDO ANDRÉ GORZ1
}

\author{
Willy Gianinazzi*
}

\begin{abstract}
Ao analisar a evolução do capitalismo contemporâneo (automação, informatização, globalização), André Gorz sublinha suas consequências sociais (desemprego, precariedade, desigualdades, pobreza). Focando sua análise nas transformações do trabalho (valorização da inteligência e da imaginação) que acompanham essas mutações, ele decifra a emergência de uma inteligência coletiva de que o capitalismo tenta se apropriar, mas que se confunde com a "produção de si", isto é, com atividades nas quais as faculdades pessoais podem se desenvolver fora do trabalho subordinado. Uma riqueza de novo tipo é criada; ela é qualitativa e fundada nos vínculos sociais de cooperação. A renda básica é concebida como uma âncora existencial transitória, que permite esse salto.
\end{abstract}

Palavras-chave: André Gorz. Produção de si. Capitalismo cognitivo. Renda básica.

\section{INTRODUÇÃO}

Poucos pensadores como André Gorz têm se empenhado em renovar continuamente a sua reflexão sem jamais se dar por satisfeito com o ponto de chegada, sempre provisório. Até seu último dia, Gorz se ateve à tarefa teórica de abrir os canais de saída da dominação capitalista e de destruição do modo de vida que essa dominação implica. Cerca de dez anos após a sua morte em 22 de setembro de 2007, aos 84 anos de idade, a publicação de sua primeira biografia intelectual na França, sob os nossos cuidados (Gianinazzi, 2016), deu lugar a julgamentos maravilhados que o qualificam de "precursor", de "visionário", e que se perguntam se não se descobriu, nesse ecologista radical, "o grande pensador do século XXI”. O Partido socialista francês confirmou

* Historiador e pesquisador independente. willy.gianinazzi@ehess.fr

${ }^{1}$ Traduzido do francês por Celia Maria Marinho de Azevedo. a atualidade de seu pensamento ao escolher como candidato à eleição presidencial de 2017 Benoît Hamon, cujas análises econômicas e proposições políticas lembram surpreendentemente os teoremas gorzianos.

\section{UM PENSADOR PARA O SÉCULO XXI}

Se, todavia, Gorz aparece como um oráculo a predizer o declínio do capitalismo e a possibilidade de um outro mundo que seja humanamente desejável, não é por uma intuição providencial, mas porque ele não cessa de descortinar as tendências tempestuosas de nosso mundo ingresso na era do Capitaloceno.

Se, desde 1954, ele investiga (apesar de não se inquietar em demasia) o aquecimento climático devido à poluição industrial, cuja consequência será o aumento do nível dos oceanos, é simplesmente porque ele perscruta a literatura científica. Se, desde 1959, em seu livro Morale de l'histoire, ele denuncia a obsolescência psicológica das mercadorias submetidas à sua renovação incessante, o que induz, por sua vez, seu desperdício e sua escassez 
necessária (para manter o preço delas), é porque ele conhece as estratégias de manipulação dos desejos e das necessidades que o marketing norte-americano lança de propósito para submeter os indivíduos ao círculo infernal da produção-consumo. Se, desde 1972, e depois em seu manifesto Écologie et Liberté (1977), ele prega o decréscimo econômico dos países ricos e se opõe à obsolescência programada, exigindo a fiscalização da durabilidade dos produtos, é porque a consciência ecológica do desastre planetário, para o qual a lógica produtivista conduz inexoravelmente, já está viva, sobretudo graças ao célebre relatório Meadows (Limites do Crescimento, 1972).

Mas, acima de tudo, se Gorz demonstra clarividência na análise daquilo que se tornou hoje a "megamáquina tecnocapitalista" apoiada nas finanças, é porque, há mais de quarenta anos, nós vivemos uma mesma situação: ingressamos numa fase indolente do capitalismo, que se prolonga por sobressaltos e soluções enganosas até nossos dias. Não poderíamos compreender de outro modo a sagacidade de Gorz, quando ele declara, em 1983:

No que concerne à crise econômica mundial, estamos no início de um longo processo que se prolongará por decênios. O pior ainda está diante de nós, ou seja, o colapso financeiro de grandes bancos e provavelmente também dos Estados" (Gorz apud Gianinazzi, 2016, p. 330-331).

A pertinência de sua análise decorre também do fato de ter sido "elaborada em um contexto de capitalismo avançado, em países de alta industrialização”, ao contrário da conjuntura social brasileira, que não vivenciou "o mesmo desenvolvimento das forças produtivas da Europa e dos Estados Unidos"; talvez seja por isso que a sociologia brasileira tem frequentemente assimilado mal suas teses em matéria de evolução do trabalho e das classes sociais $^{2}$ (Grazia, 2014).

Tudo começou no final de 1973, com um epifenômeno, a crise petrolífera mundial. "Os

${ }^{2}$ Reconheçamos que Josué Pereira da Silva, que não é mencionado nesse estudo, é uma exceção.
Trinta gloriosos” (1945-1976) chegam ao fim, como se diz na França de acordo com o economista Jean Fourastié. A tendência (ciclo longo à la Kondratiev) se inverte. Nos países desenvolvidos, assiste-se à expansão da divisão de trabalho - pela subcontratação, depois pela globalização -, à automatização seguida da robotização, ao salto exponencial da informática seguido da Internet. Tudo isso constitui a dita "terceira revolução industrial”, cuja característica é a novidade de pôr fim à preponderância da indústria (a denominação dessa revolução é, pois, imprópria ${ }^{3}$ ), sem nada trazer à cena que estimule uma nova onda de crescimento. Doravante, nesses países, o crescimento será nulo ou se elevará um pouco acima de zero.

No seguimento de suas obras escritas nos anos 1980, Adeus ao Proletariado e Metamorfoses do Trabalho, Gorz (1982, 2003b) descreve em detalhe o sentido dessa mutação estrutural, cujas consequências sobre a vida das pessoas ele põe em evidência. O desemprego, a precariedade, as desigualdades sociais e o nível de pobreza alcançam picos jamais igualados desde o final da Segunda Guerra Mundial. A destruição dos empregos tradicionais nos setores atingidos por essas mutações é compensada pela criação de novos empregos nos serviços, porém, não suficientemente para reabsorver o aumento da população ativa. $\mathrm{O}$ desemprego, ao atingir níveis muito elevados, torna-se estrutural.

Assim que assistimos às retomadas cíclicas (ciclo à la Juglar) da economia, percebemos, tal como nos Estados Unidos dos anos 1980, que a expansão do emprego concerne às atividades pouco qualificadas, como na restauração, na limpeza, no auxílio às pessoas (care). A retomada econômica atual, que se vê, por exemplo, na Alemanha, na Inglaterra, na Dinamarca e nos Estados Unidos, é significativa das mutações profundas que perpassam o trabalho há decênios: aquilo que se chama retorno ao "pleno emprego", que se situa, doravante, em

${ }^{3}$ Alvin Toffler tem razão de preferir a expressão mais vaga de A Terceira Onda (1980). 
níveis elevados de desemprego "técnico", 4 devido ao turn over global $-4 \%$ a $6 \%$ da população ativa! -, esconde para além da renovação de uma fina camada de empregos altamente qualificados, a proliferação dos "empregos de merda” (bullshit jobs) - alienantes, sub-pagos e socialmente inúteis -, ou seja, a instalação definitiva de uma mão de obra cada vez mais numerosa na precariedade e na insegurança de vida. Também Gorz não deixou de perceber o declínio do emprego em tempo integral e durante a vida em benefício de formas múltiplas de trabalho precário, que vão da prestação de serviço do trabalhador independente (contrato pontual, tarefa, freelance, etc.) ao trabalho interino, intermitente, em tempo parcial subordinado, até o trabalho gratuito voluntário (30.000 pessoas forneceram generosamente a logística dos jogos olímpicos no Rio!).

\section{AUTONOMIA E INTELIGÊNCIA CO- LETIVA}

O modo de produzir e a natureza do trabalho também foram profundamente transformados pela terceira revolução industrial. Assim como os futuristas norte-americanos Alvin Toffler (1980) e Jeremy Rifkin (2001), Gorz chama a atenção para isso em seus dois últimos ensaios, Misérias do Presente, Riqueza do Possível, publicado primeiramente em 1997, e O Imaterial, em 2003. A automatização eliminou os ofícios, mas, incidentalmente, exaltou as faculdades de controle, de organização e de reativação dos engenheiros. A digitalização desqualificou os ofícios e, ao mesmo tempo, enfatizou a polivalência profissional dos indivíduos, dando livre curso ao manejo virtuoso das Tecnologias de Informação e Comunicação (TICs). A administração foi transformada; ela conduziu ao enriquecimento e à intelectualização das tarefas, solicitou as capacidades

4 “Técnica” no sentido em que um período de desemprego obrigatoriamente transcorre entre a perda e o retorno ao emprego. A importância da formação permanente torna-se, agora, uma variável determinante do nível de desemprego. criativas e imaginativas, valorizou a iniciativa e a comunicação. Ela se fez acompanhar da exigência de implicação e de devotamento total da pessoa a seu trabalho, sem limite de tempo. Trata-se de O Novo Espírito do Capitalismo (2009), descrito, após Gorz, pelos sociólogos Luc Boltanski e Ève Chiapello.

Se considerarmos o trabalho contemporâneo no nível mais moderno e estratégico de sua expansão - ou seja, abstraindo o trabalho propriamente material de transformação ou execução -, ele se caracteriza, segundo Gorz, por dois traços eficientes. O primeiro é a $a u-$ tonomia: o trabalho vivo alcança a mais alta produtividade na medida em que a autonomia do trabalhador, seja ele assalariado ou independente, é reconhecida, mesmo encorajada. O segundo é a inteligência, porque, doravante, "[...] a forma mais importante da força de trabalho é o intelecto" (Gorz, 2004, p. 13). Portanto, o processo de produção não se reduz mais ao processo de "trabalho imediato", que consiste em "fabricar" o produto. De agora em diante, o valor agregado é dado principalmente pelos fatores de produção que decorrem de um trabalho "mediato" invisível, imaterial, autônomo: o trabalho de inteligência (e de afeto).

Mas suas novas qualidades produtivas intelectuais (e afetivas) não estão mais exclusivamente ligadas ao mundo da produção, como era o caso da ciência incorporada nas máquinas e na organização técnica do trabalho, embora sejam imanentes às próprias pessoas. Enquanto os conhecimentos científicos se cristalizam no "capital fixo", essa inteligência coletiva advém do "capital humano" como "saber vivo". É a grande novidade. Ao apoiar-se sobre um bom nível de instrução geral, sobre o acesso à TIC, essa intelectualidade de massa é feita de saberes experimentados que são também o saber-fazer espontâneo e informal que quase não pode ser ensinado.

O que impressiona - escreve Gorz - é que não se trata aqui nem de conhecimentos, nem de qualificações profissionais [...] Todas essas qualidades e essas faculdades são habitualmente próprias dos prestadores de serviços pessoais, dos fornecedores 
de um trabalho imaterial impossível de quantificar, estocar, homologar, formalizar e até mesmo de objetivar (Gorz, 2005a, p. 17).

Lá, onde os discípulos de Michel Foucault veem, nesse tipo de trabalho, a subsunção da vida ao capital - o italiano Andrea Fumagalli (2016) fala de "capitalismo biocognitivo" -, reside, segundo Gorz, uma parte do problema encontrado pelo capitalismo. Isso significa, de fato, que o capital humano não é mensurável e que a estimativa dos ativos imateriais de uma firma é uma operação muito aleatória - e, no entanto, essencial para os acionistas ou as instituições de crédito. Não é só isso: ao reduzir a uma parte secundária o trabalho imediato como fator de produção, o trabalho imaterial remove, do tempo de trabalho, como Karl Marx (2011) o previu, sua função clássica de medida do valor produzido. O capital, que sempre necessitou de padrão para a sua valorização no mercado, não parece mais repousar sobre algo. Aos olhos de Gorz (apud Gorz; Vincent, 2001), valor e sobretrabalho são as categorias que perdem sentido. A dominação do capital não diminui por isso, pois ela se mantém total: a função reguladora do valor diminui, ela perde o lugar, no plano da gestão, em relação à especulação financeira dos conselhos de administração, que registram mais do que os lucros tirados da produção, e no A plano social, em relação a uma redução do custo do trabalho graças às relações salariais cada Фั่ vez mais flexíveis.

\section{放}

\section{RENDIMENTO DE MONOPÓLIO E} PRODUÇÃO DO CONSUMIDOR

Para Gorz, não é tudo. A expansão e a não mensurabilidade da inteligência coletiva impulsionam o capitalismo a se apropriar dela, formalizando-a nos conhecimentos que ele não pode privatizar diretamente, mas aos quais ele anexa um valor mercantil, cujo acesso é privatizado pelos artifícios técnicos (códigos de acesso, etc.) ou jurídicos (direitos de autor, patentes, etc.) - como Rifkin o viu bem também em A era do acesso (2001). Gorz (2005a p. 4448) assimila essa operação à constituição de um "rendimento de monopólio". A seu ver, ela nunca se completa, nem é satisfatória jamais, não somente porque o saber ultrapassa o quadro posto pelo trabalho e pode circular livremente sob sua forma digitalizada, mas também porque o valor mercantil de seus produtos não para de diminuir na proporção de sua reprodutibilidade infinita por um custo marginal ínfimo (é o caso dos produtos farmacêuticos ou dos produtos digitalizados - software, música, filmes). Para lutar contra a tendência à "gratuidade" dos produtos de inteligência, o capital empenha-se em organizar sua "escassez".

Todas essas dificuldades enfrentadas pelo processo de valorização explicam por que Gorz (2005a, p. 7) pode afirmar sem nuance: "O 'capitalismo cognitivo' é a crise do capitalismo em seu sentido mais estrito”.

A escassez dos produtos imateriais, que salvaguarda o seu valor, pode, portanto, ser obtida por meio de sua monopolização. Outra astúcia consiste em anexar nesses produtos, assim como em toda mercadoria, as novas qualidades simbólicas, afetivas e estéticas que as tornam únicas no tempo de uma campanha de marketing. Ou ainda, como o mostra "com excelência” Naomi Klein, em sua afamada obra Sem Logo (2002), que cuidar da imagem da marca se torna, de ora em diante, o essencial do valor do produto. Tudo isso pressupõe o empenho na "produção do consumidor" (Gorz, 2005a, p. 4853), ou seja, no trabalho de marketing para que a subjetividade do consumidor corresponda à valoração simbólica das mercadorias que essa mesma subjetividade contribui para modelar em retorno pela solicitação de opinião ou da contribuição do consumidor. A propósito, os anglo-saxões falam em crowdsourcing.

\section{A PRODUÇÃO DE SI}

"Ao tornar-se a base de uma produção de valor fundada sobre a inovação, a comunica- 
ção e a improvisação contínua, o trabalho imaterial tende finalmente a se confundir com um trabalho de produção de si" (Gorz, 2003a, p. 120). Dito de outro modo,

[...] o capital fixo não tem mais uma existência separada; ele está subsumido, interiorizado por homens e mulheres que têm a experiência prática concreta na qual a principal força produtiva não é nem o capital-máquina nem o capital-dinheiro, mas a paixão viva com a qual imaginam, inventam e incrementam suas próprias capacidades cognitivas ao mesmo tempo em que incrementam igualmente sua produção de conhecimentos e riqueza. A produção de si é, aqui, produção de riqueza, e vice-versa (Gorz, 2016, p. 14).

"A produção de si" é um conceito elaborado por Gorz. Ele tem por base a expressão idêntica que Gorz encontra em Alain Touraine, sociólogo francês por quem ele tem grande apreço. Em sua Crítica da Modernidade, Touraine (1994) o utiliza para designar o Sujeito se fazendo. Em Gorz, esse conceito frutifica em contato com autores como o psicanalista Féliz Guattari $^{5}$, com o qual ele compartilha a sua teoria ecosófica - mental, sociopolítica e ecológica (Guattari, 1990) - ou como o sociólogo Roger Sue (2004), que enfatiza a “[...] passagem do indivíduo produtivo à produção do indivíduo, onde o indivíduo é menos o instrumento de sua produção que sua matéria prima”. Esse conceito pretende significar a subjetivação singular de um fundo cultural comum - a inteligência coletiva -, que consiste "[...] essencialmente em adquirir, desenvolver, enriquecer as capacidades de prazer, de ação, de comunicação, de criação, de cognição, etc., como fins em si mesmos" (Gorz, 2001, p. 80). É graças ao peso crescente dos conteúdos imateriais na natureza das mercadorias que a tendência à autoprodução ganha de novo terreno.

Todavia a liberdade de agir e o desabrochar pessoal do indivíduo, que parecem constituir e permitir essa produção de si, não são mais do que virtuais. Isso porque a produção de

5 Em vários escritos de Guattari, encontram-se expressões como "produção singular da existência", "produção da existência humana”, "produção de si como sujeito", "produção de subjetividade", etc. si representa uma espécie de "acumulação primitiva”, em que as empresas jogam quase que gratuitamente. Os administradores das grandes firmas vigiam para que a "autonomia" da produção de si, prova de todas as suas virtudes produtivas, seja preservada, ao transmitirem uma ilusão de metamorfosear colaboradores, prestadores, consultores e outros incumbidos da missão em pequenos empreendedores autônomos, sejam eles assalariados ou independentes.

\begin{abstract}
Assim - escreve Gorz em 1998 -, existem hoje indústrias de alta tecnologia [por exemplo, Google] que exigem que seus empregados despendam tempo envolvidos com outros assuntos que não a produtividade empresarial - filosofia, dança, música, etc. A criatividade é desejada pela direção da empresa porque ela observou que a força de trabalho torna-se apática, que sua imaginação inventiva desaparece quando ela não pode usar o tempo livremente como pessoas criativas (Gorz, 1998, p. 184) .
\end{abstract}

Mas, longe de desaparecer, a coerção que o trabalho impõe não é menos interiorizada, e a parte da autonomia que os "trabalhadores cognitivos" experimentam no trabalho deles não suprime em nada a "heteronomia" das funções impostas por uma organização devido a uma meta pré-estabelecida que lhes escapa. Essa "autonomia no seio da heteronomia" é, portanto, "[...] uma autonomia dominada, sujeitada, subalterna, instrumentalizada que não tem de fato os meios de se pretender ela mesma como exigência de emancipação total" (Gorz apud Gollain, 2000, p. 226).

Não obstante, a essência subjetiva da produção de si abriga as verdadeiras potencialidades da autonomia, as quais fazem dessa questão o jogo de um "conflito central". Potencialidades que não se confundem com a "autovalorização" ou o autoempreendimento, isto é, com o anúncio de venda de si mesmo como mercadoria - o filósofo autonomista Antonio Negri foi pouco feliz ao inventar a noção ambígua de autovalorização, que contém o princípio motor do capitalismo, mas que, para ele,

${ }^{6}$ Tradução modificada. 
é uma categoria antieconômica (Gorz, 2007, p. 104). Isso porque a importância do tempo dedicado ao trabalho invisível, ou seja, às "atividades nas quais as faculdades pessoais podem se desenvolver", terminará - espera Gorz - por impulsionar as pessoas a "[...] contestarem a lógica do capital. O que hoje é necessário ao capitalismo também contém o germe da exigência de sua ultrapassagem” (Gorz, 2005b).

\section{OUTRA ECONOMIA E OUTRA RI- QUEZA}

Nos tempos de hoje, novas formas de trabalho auto-organizado aparecem através daquilo que se chama economia cooperativa, compartilhada, solidária e impulsionada pelo êxodo urbano de famílias ecoalternativas ${ }^{7}$ agropastoral extensiva. Ao lado do setor privado e do setor público, um terceiro setor está em nascimento. Frente à rarefação relativa e à indigência dos empregos remunerados, que não passam de um ganha-pão, desenvolve-se, em particular entre os jovens, a vontade de produzir eles mesmos riquezas que não têm necessariamente um valor mercantil, mas que têm um valor em si mesmas.

Tais riquezas são vínculos sociais de cooperação.

Em suma, as redes cooperativas constroem um espaço público culturalmente e praticamente crítico em relação ao sistema capitalista. O dinheiro deixa de ser a medida da riqueza e a auto-organização libera os indivíduos da impotência e da dependência. Encontramos aí a inspiração original do movimento operário (Gorz, 2005b).

Na entrevista destinada ao Brasil, de onde tiramos a citação acima, Gorz (2005b) acrescenta:

Parece-me que o Brasil desempenha um papel de vanguarda nesse sentido. Suas cooperativas procuram combater o desemprego não mais por meio da criação de empregos assalariados, mas dando aos desempregados os meios de produzir coletivamente para necessidades comuns. O trabalho é então com-

${ }^{7}$ Esse fenômeno ganhou uma certa amplitude sobretudo na França. preendido como algo que se faz, e não algo que se tem. O trabalho liberado da tirania do emprego é um poder que você toma para si, enquanto o emprego é uma dependência. Encontramos também, nas comunas rurais da Índia, o exemplo de cooperativas de autoprodução comunal. Mas, no Brasil, parece-me que o novo cooperativismo carrega a concepção de um novo modelo de desenvolvimento: uma definição de riqueza que converge com aquela sugerida por Amartya Sem [economista indiano que ganhou o "Prêmio Nobel" em 1998]. Creio que há, no Brasil, mais do que em outros lugares, o melhor e o pior, mas se trata também de um país no qual a parte do melhor e a resistência ao pior não cessam de ganhar terreno na consciência popular.

\section{A RENDA DE EXISTÊNCIA}

A evolução contemporânea do capitalismo comporta um problema assim formulado por Gorz (2007, p. 95-96):

A revolução microeletrônica permite produzir quantidades crescentes de mercadorias com um volume decrescente de trabalho, de sorte que, cedo ou tarde, o sistema deve colidir com seus limites internos. O capitalismo que se automatiza até a morte deverá buscar a sua sobrevivência por meio de uma distribuição de poder de compra que não corresponde ao valor de um trabalho.

Nos anos 1980, Gorz (1983, p. 118) pensava que a economia de trabalho permitida pela automatização oferecia a possibilidade de uma “[...] redução massiva da duração do trabalho com garantia de um ganho social para a vida". Ele retomava a ideia do economista e sindicalista sueco Gösta Rehn, para quem era preciso

[...] permitir que cada um tirasse, dentro de certos limites, ao longo de toda a sua vida ativa, parcelas de sua aposentadoria, ao parar durante períodos mais ou menos longos (durante os quais se continuava a ser pago) de realizar um trabalho (assalariado) para se dedicar a atividades diferentes: por exemplo, estudar, cultivar a terra, construir sua casa, ocupar-se de seus filhos, militar, viajar, pintar, etc. (Gorz, 1983, p. 189).

Ao trabalho descontínuo deve corresponder um salário contínuo. A “renda social 
garantida" preconizada por ele permanecia, portanto, ligada a um certo volume de trabalho que era necessário realizar ao longo da vida, mas sem relação direta com ele: "É necessário que a renda distribuída pare de ser uma função da quantidade de trabalho fornecida para se tornar função da quantidade de riqueza que a sociedade escolheu produzir" (Gorz, 1983, p. 189). A partir precisamente de 1996, Gorz radicaliza o seu ponto de vista ao aprofundar a ruptura entre o trabalho e a renda: esta última deve ser garantida independentemente da participação ou da disponibilidade de criação de riquezas valorizadas pelo capital. Isto porque, como vimos, há outras riquezas que contribuem para o bem-estar humano: não se trata daquelas que, postas sob o jugo do valor e tendo produzido matérias e energias em quantidade crescente, levam à exaustão e à degradação da biosfera, conduzindo a humanidade à sua perda. Gorz aderia, assim, à ideia de uma renda de existência sem contrapartida alguma. Desse modo, ele operava uma inversão total da relação entre trabalho e renda: não era mais preciso constranger o trabalhador a trabalhar para ter uma renda, separando a questão dos fins verdadeiros do trabalho, mas ter uma renda para obrar sem constrangimento, tendo sob domínio os fins de sua atividade. "Nesta perspectiva, a renda básica garantida tem um sentido: é uma arma potencialmente sempre mais contundente para a superação do capitalismo e a saída de uma sociedade prostrada diante da valorização do capital” (Gorz, 1998, p. 128).

Em Misérias do Presente, Riqueza do Possível, Gorz (2004, p. 93) expõe um conjunto de políticas que vão nesse sentido. Três delas são indicadas aqui:

Garantir a todos uma renda suficiente; combinar redistribuição de trabalho e domínio individual e coletivo do tempo; favorecer o florescimento de novas socialidades, de novos modos de cooperação e de troca através dos quais os elos sociais e a coesão social sejam criados fora do assalariamento.

A redução legal do tempo de trabalho e a possibilidade do tempo de trabalho parcial escolhido (e não sofrido) são as medidas que permitem favorecer um tempo liberado, de onde se podem tirar atividades autodeterminadas. Trabalho heterônimo e atividades autônomas poderiam se imbricar na vida multiativa de cada um.

Nesse dispositivo de três vias, a ideia de uma renda básica é fundamental. Essa renda deve ser "suficiente" para evitar a pressão ao emprego que favoreceria a queda dos salários e a proliferação de empregos indignos. É o que, nesse último caso, a faria equivaler a uma subvenção indireta aos patrões (é isso, sobretudo, que desejam os partidários neoliberais da renda básica, como o economista Milton Friedman (1984), que defendia, nos anos 1960, a ideia de um imposto negativo para os pobres). É por isso que Gorz evita, em geral, a expressão "renda básica" e prefere falar de "alocação universal" ou de "renda de existência". ${ }^{8}$ Essa renda deve também ser destinada a todos e sem condição alguma: é assim que se evita a armadilha do assistencialismo e do controle social, e se tira daqueles que dispõem de grandes rendas, cuja alocação será recuperada por um imposto progressivo. Para Gorz, essa renda garantida não é uma incitação ao fazer nada, mas, ao contrário, um multiplicador de atividades. Ela é uma seguridade para o indivíduo que, de ora em diante, pode se devotar livremente à produção de sua vida.

Ao final de sua vida, após a publicação de O Imaterial na França, Gorz voltou ao sujeito. ${ }^{9}$ Influenciado, então, pelo radicalismo anticapitalista dos partidários da crítica do valor, ele lê Moishe Postone e Robert Kurz, mantém uma correspondência contínua com o militante do software livre, o alemão Stefan Meretz, e com o jornalista Franz Schandl, editor da revista Streifzüge em Viena. Ele admite que, ao conceder o dinheiro para o consumo, a renda de existência não faz mais do que reproduzir

${ }^{8}$ As duas últimas expressões foram postas em circulação, respectivamente, pelos cofundadores do Basic Income Earth Network (BIEN), Philippe Van Parijs e Yoland Bresson.

9 Para uma apresentação das evoluções de Gorz até esse momento, ver Josué Pereira da Silva (2010). 
o fetichismo do dinheiro e da mercadoria, tendo como resultado a manutenção dos beneficiários sob o jugo do capitalismo. A tradução em alemão de $O$ Imaterial, lançada em 2004, é reveladora desses novos avanços teóricos de Gorz. O item intitulado "Fundamentos da renda de existência" é alterado e muda de título: "A ambiguidade da renda de existência". ${ }^{10}$ Gorz (2005a, p. 76) termina, portanto, por conceber essa ideia como uma medida transitória, que "[...] não serve para a atualização contínua de uma existência dependente da mercadoria, mas para distribuição de bens que são produzíveis somente em instalações que se baseiam na divisão do trabalho por várias regiões, e sem as quais (por exemplo, os semicondutores) a autoprodução local não seria possível”. ${ }^{11}$

Não houve tempo para ele aprofundar a perspectiva que começava a visualizar, ou seja, aquela capaz de ultrapassar a circulação monetária, o que permitiria a proliferação de "bens comuns". Isso corresponderia a "uma economia para além do trabalho-emprego, do dinheiro e da mercadoria, fundada na partilha comum dos resultados de uma atividade compreendida como comum” (Gorz, 2016, p. 74).

Recebido para publicação em 05 de junho de 2017 Aceito em 31 de julho de 2017

\section{REFERÊNCIAS}

BOLTANSKI, L.; CHIAPELLO, E. O novo espírito do capitalismo. Bela Vista, SP: WMF Martins Fontes, 2009.

FRIEDMAN, M. Capitalismo e liberdade. São Paulo: Abril Cultural-Victor Civita, 1984.

FUMAGALLI, A. O conceito de subsunção do trabalho ao capital: rumo à subsunção da vida no capitalismo biocognitivo, Cadernos IHU Ideias, São Leopoldo, RS, ano 14, n. 246, p. 4-22, 2016.

- GIANINAZZI, W. André Gorz: une vie. Paris: La Découverte, 2016.

GOLLAIN, F. Une critique du travail: entre écologie et socialisme. Paris: La Découverte, 2000.

(3)

${ }^{10}$ A tradução em português baseada sobre essa edição modificada e aumentada, publicada pela Rotpunkt, em Zurique, mantém, porém, ambos os títulos.

11 Tradução modificada.
GORZ. A. Adeus ao proletariado. Rio de Janeiro: ForenseUniversitaria, 1982.

GORZ. A. Ecológica. São Paulo: Annablume, 2016.

GORZ. A. O fim do trabalho assalariado: entrevista com Thomas Schaffroth. Lugar comum, Rio de Janeiro, n. 5/6, p. 179-189, maio/dez. 1998.

GORZ. A. O Imaterial: conhecimento, valor e capital. São Paulo: Annablume, 2005a.

GORZ. A. Les chemins du paradis. Paris: Galilée, 1983.

GORZ. A. L'immatériel: connaissance, valeur et capital. Paris: Galilée, 2003a.

GORZ. A. Metamorfoses do trabalho. São Paulo: Annablume, 2003b.

GORZ. A. Misérias do presente, riqueza do possível. São Paulo: Annablume, 2004.

GORZ. A. Ócio revolucionário. Folha de S. Paulo, São Paulo, 30 jan. 2005b. Ilustríssima. Suplemento.

GORZ. A. Penser l'exode de la société du travail et de la marchandise, Mouvements, Paris, n. 50, p. 95-106, 2007.

GORZ. A. La personne devient une entreprise: Note sur le travail de production de soi, EcoRev', Paris, n. 7, p. 7-10, 2001.

GORZ. A; VINCENT, J.-M. Dialogue avec André Gorz. Variations, Lyon, n. 1, p. 9-18, 2001.

GRAZIA, M. R. Classe e estratificação social: analise da influencia da teoria de "fim das classes" do Adeus ao Proletariado de André Gorz na sociologia Brasileira. In: SEMANA DE CIENCIAS SOCIAIS UNIFESP, 7., 2014, São Paulo. Anais... São Paulo: Blucher, 2014. Introdução disponível em: <estudosdotrabalho.org/texto/gt9/adeus. pdf $>$. Acesso em: 14 outubro 2017.

GUATTARI, F. As três ecologias. Campinas: Papirus, 1990.

KLEIN, N. Sem Logo: a tirania das marcas em um planeta vendido. Rio de Janeiro: Record, 2002.

MARX, K. Grundrisse: manuscritos econômicos de 18571858: esboços da crítica da economia politica. São Paulo: Boitempo l, 2011.

RIFKIN, J. A era do acesso. São Paulo: Makron Books, 2001.

SILVA, J. P. da. André Gorz e renda básica: uma história de conversão crítica. In: CONGRESSO BIEN, 13., 2010, São Paulo. Anais... São Paulo: FEA, 2010. Disponível em: $<$ sinteseeventos.com.br/bien/pt/programa.htm $>$. Acesso em: 14 out. 2017.

SUE, R. Renovar a ligação social: liberdade, igualdade, associação. Porto: Campo das Letras, 2004.

TOURAINE, A. Crítica da modernidade. Petrópolis: Vozes, 1994.

TOFFLER, A. A terceira onda. Rio de Janeiro: Record, 1980. 


\section{IMMATERIAL CAPITALISM AND PRODUCTION OF THE SELF ACCORDING TO ANDRÉ GORZ}

\author{
Willy Gianinazzi
}

In analyzing the evolution of contemporary capitalism (automation, informatization, globalization), André Gorz emphasizes the social consequences (unemployment, precarization, inequalities, poverty). Focusing on the transformations of labor (valorization of skills and imagination) that accompany these changes, he deciphers the rise of a general intellect, that capitalism tries to appropriate, but that confuses itself with the "production of the self", that is, with activities which personal faculties can develop outside subordinated labor. A new, qualitative type of wealth, based on cooperative social links, is created. A basic income is thought of as a transitory existential anchor that makes this flight possible.

KEY-wORDS: André Gorz. Production of the self. Cognitive Capitalism. Basic Income.

\section{CAPITALISME IMMATERIAL ET PRODUCTION DE SOI SELON ANDRÉ GORZ}

\author{
Willy Gianinazzi
}

En analysant l'évolution contemporaine du capitalisme (automatisation, informatisation, mondialisation), André Gorz en souligne les conséquences sociales (chômage, précarité, inégalités, pauvreté). En analysant les transformations du travail (valorisation de l'intelligence et de l'imagination) qui accompagnent ces mutations, il décrypte l'émergence d'une intelligence collective que le capitalisme essaie de s'approprier, mais qui se confond avec la "production de soi", c'est-à-dire avec les activités dans lesquelles les facultés personnelles peuvent se développer en dehors du travail subordonné. Une richesse de type nouveau se crée, elle est qualitative et fondée sur des liens sociaux de coopération. L'allocation universelle ou revenu d'existence est conçue comme une sécurité existentielle transitoire permettant cet essor.

Mots-Clés: André Gorz. Production de soi. Capitalisme cognitif. Revenu d'existence.

Willy Gianinazzi - Juntou-se ao conselho editorial de Cahiers Georges Sorel (então Mil neuf cent. Revue d'histoire intellectuelle) em 1984. Secretário de Mil neuf cent, d'Actuel Marx (1992-1994), membro da equipe editorial da L'Homme et la société (2003-2007) e EcoRev'. Revue critique d'écologie politique (desde 2016). Membro do partido francês Os Verdes de 1989 a 1996. Publicações: André Gorz, uma vida. Paris, La Découverte, 2016, 383 p.; Nascimento do mito moderno. Georges Sorel e a crise do pensamento acadêmico (1889-1914). Paris, Ed. de la Maison des Sciences de l'homme, 2006, 231 p.; Intellettuali in bilico. "Pagine libere" i sindacalisti rivoluzionari prima del fascismo. Milão, Ed. Unicopli, 1996, 289 p.; L'itinerario di Enrico Leone. Liberismo e sindacalismo nel movimento operaio italiano. Milão, Franco Angeli, 1989, 245 p. 
